\title{
Differences in mass-balance calculations resulting from alternative sampling and estimation techniques on Glacier No. 1, Tien Shan, Ghina
}

\author{
Kelly Elder, Richard KattelmanN, \\ Department of Geography and CSL/CRSEO, University of California, Santa Barbara, CA 93106, U.S.A. \\ SERGei N. UshnuRTSEV, \\ Institute of Geography, Academy of Sciences of the USSR, Staromonetny 29, Moscow 109017, USSR \\ YANG DAQING \\ Lanzhou Institute of Glaciology and Geocryology, Academia Sinica, Lanzhou 730000, China \\ AND Alexander Chichagov \\ 1367 Leaside Avenue, Ottawa, Ontario K1Z 7R4, Canada
}

\begin{abstract}
In May of 1990, three research groups from China, the Soviet Union and the United States visited Glacier No. 1 in the Ürümqi river basin, Xinjiang Uygur Autonomous Region, northwestern China, in a cooperative effort to examine differences in mass-balance calculations resulting from sampling and estimation procedures. Three different snow-depth data sets were collected consisting of: (1) high-resolution depth transects covering the glacier, (2) depths taken from the permanent stake network, and (3) an intermediate data set constructed using the stake network and supplementary depth data from locations not covered by the stake network. The glacier was divided into ten elevation zones and the data were registered to a digital elevation model for analysis. Results show that the permanent stake network provides an accurate estimate of total mass balance if certain techniques are used for extrapolation to higher elevations, although estimates of mass balance for particular regions of the glacier are not accurate. Some regions were overestimated while others were underestimated, leading to a good overall estimate. The intermediate-resolution data set provided better within-zone estimates of mass balance, but was less accurate than the stake network for total mass balance.
\end{abstract}

\section{INTRODUGTION}

The Ürümqi river basin drains northward from the Tien Shan to the capital city Urümqi, of the Xinjiang Uygur Autonomous Region, China. The importance of the headwater glaciers for water supply has led to intensive study of the ice masses, and of Glacier No. 1 in particular. In May 1990, three research groups from China, the Soviet Union and the United States visited Glacier No. 1. Field work was conducted by all three groups in a cooperative effort to examine differences in mass-balance calculations resulting from sampling and estimation procedures. This field exercise and data analysis sought to answer several questions. First, can snow water equivalence (SWE) be accurately measured by a relatively small number of points on a glacier surface or do we need intensive surveys? How many samples are needed to reach an acceptable level of accuracy and how should these samples be spatially distributed? These questions are important for both basic mass-balance estimations and for ground-truthing air- and space-borne sensors.

The large number of scientists in the field allowed us to gather high-resolution data that is not feasible on an operational basis. The permanent stake network and normal sampling scheme covers approximately $50 \%$ of the glacier surface, generally confined to gentle slopes and lower elevations. Comparisons of the data covering the entire glacier with the stake network data allowed us to examine the accuracy of the stake network when used alone in mass-balance calculations. Stake networks are used on many glaciers throughout the world to measure mass balance (Paterson, 1981; Kotlyakov and Krenke, 1982) and an assessment of error is valuable.

\section{STUDY SITE}

Glacier No. 1 (Fig. 1) has an area of 195 ha $(1 \mathrm{ha}=$ $\left.10^{4} \mathrm{~m}^{2}\right)$, an elevation range from about 3750 to $4480 \mathrm{~m}$ 


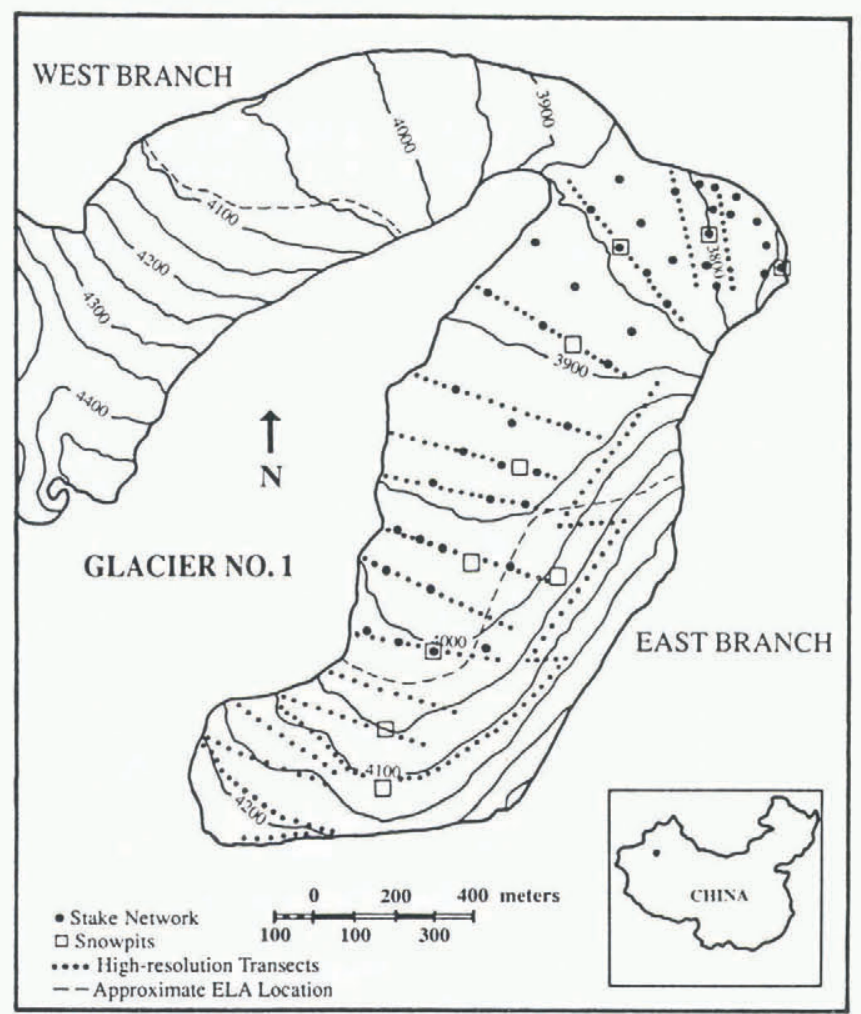

Fig. 1. Glacier No. 1, east and west branches. Elevations in meters above sea level, $50 \mathrm{~m}$ contour intervals (adapted from Echelmeyer and Wang, 1987). High-resolution transect refers to data set 1, stake locations are for permanent stake network (data set 3), and snow-pit locations are where density was measured. Data set 2 consisted of all points in the stake network, as well as a small subset of the transect data (153 points located primarily in zones $4-10$ ).

a.s.l., and a northeast exposure. The glacier consists of two streams referred to as the east and west branches, 116 and 79 ha in area, respectively. Most of the precipitation occurs in the summer with $70 \%$ falling from May through September. Less than 10\% falls from December through February.

\section{FIELD METHODS}

Snow depth was measured by two basic techniques. The first measured depth at 5 and $10 \mathrm{~m}$ intervals along transects. Portable aluminum depth probes capable of measuring depths up to $10 \mathrm{~m}$ were used for the transects. The second technique used the permanent stake network where depth was measured directly from the stakes. Sample points were located using the stake network and landforms for visual reference, a $1: 5000$ scale topographic map with $5 \mathrm{~m}$ contour intervals, and a barometric altimeter. Many of the depth transects were measured along the stake lines allowing us to locate them accurately on the map. Most of the snow pits were excavated next to permanent stakes and others were excavated in topographically distinct locations. Snow density was measured by digging snow pits and sampling the pit wall. The winter layer was also examined in the pits to determine the extent of superimposed ice and to provide assurance that our depth probes were measuring only one year of accumulation. All field work was completed on 15 May 1990 when over 1000 depth measurements were recorded and density profiles were taken in nine snow pits. Mass-balance measurements have been made on Glacier No. 1 since 1959 by the Lanzhou Institute of Glaciology and Geocryology (LIGG). Although field work was conducted on both branches of the glacier, the analysis presented in this study is restricted to the east branch only.

\section{DATA PREPARATION}

A digital elevation model (DEM) was constructed by placing a $50 \mathrm{~m}$ grid over the 1:5000 scale $5 \mathrm{~m}$ contour map of Glacier No. 1 provided by LIGG. Elevations at the grid nodes were read directly from the contour map and recorded by arbitrary line and sample coordinates, giving 1749 elevation values over a rectangular area of $437 \mathrm{ha}$. The line and sample coordinates are arbitrary in that they are not geo-coded, because no accurate values of latitude or longitude of the basin were available at the time of the analysis. Image Processing Workbench (IPW) software (Frew and Dozier, 1986) was used to construct a DEM from the raw elevation values and to interpolate the DEM to a $5 \mathrm{~m}$ horizontal resolution. The locations of the snow pits and depth measurements were registered to the DEM, providing an $x, y$, and $z$ location for each data point. The accuracy of the elevations in the DEM constructed by this technique are less than optimal, but use of broad elevation categories in the analysis reduces the effect. The relatively accurate spatial location of the transects coupled with the gentle terrain changes found on the glacier surface make inaccuracies in the elevations insignificant for our analysis. Comparison of elevations extracted from the DEM with altimeter readings taken in the field and elevations taken from the contour map show little difference.

Mass balance was estimated using several different methods. Some of the data used and techniques employed in the mass-balance estimates were common to all methods. The SWE data were divided into ten elevation zones and the mean zone values of SWE were used in most mass-balance estimations (Andrews, 1975), with the exception of estimations made by means of the entire data sets. The elevation zones were divided into $50 \mathrm{~m}$ intervals to insure approximately equal numbers of data points in all zones, and give detailed resolution over the glacier's elevation range. The ten zones and their areas are listed in Table 1.

The same density model was used for all SWE calculations. Density was modeled as a function of elevation from the snow-pit data collected on the glacier. The mean density from each pit location was used and they are listed in Table 2. A line was fit visually to the data (Fig. 2), which was similar to results of regression models. We believe the visual fit is justified for this application. The mean density from all pits was $361 \mathrm{~kg} \mathrm{~m}^{-3}$, the standard deviation was $41.93 \mathrm{~kg} \mathrm{~m}^{-3}$, the standard error equaled $13.98 \mathrm{~kg} \mathrm{~m}^{-3}$, and the coefficient of variation was 0.116 . These statistics were based on the 
Table 1. Zones used in modeling with estimated snow density and area

\begin{tabular}{rccr}
\hline Zone & Elevation & Snow density & Area \\
& & & \\
& m a.s.l. & $\mathrm{kg} \mathrm{m}^{-3}$ & ha \\
\hline & & & \\
1 & $>3800$ & 450 & 5.9 \\
2 & $3800-3849$ & 390 & 9.7 \\
3 & $3850-3899$ & 360 & 15.5 \\
4 & $3900-3949$ & 350 & 19.4 \\
5 & $3950-3999$ & 340 & 13.8 \\
6 & $4000-4049$ & 320 & 14.7 \\
7 & $4050-4099$ & 310 & 11.5 \\
8 & $4100-4149$ & 300 & 11.2 \\
9 & $4150-4199$ & 300 & 9.9 \\
10 & $\geqslant 4200$ & 300 & 4.7 \\
\hline
\end{tabular}

Table 2. Snow pit summary: Glacier No. 1, 15 May 1990. Ice refers to superimposed ice

\begin{tabular}{lccccc}
\hline Elevation & $\begin{array}{c}\text { Snow } \\
\text { depth }\end{array}$ & $\begin{array}{c}\text { Snow } \\
\text { density }\end{array}$ & $\begin{array}{c}\text { Ice } \\
\text { depth }\end{array}$ & $\begin{array}{c}\text { Ice } \\
\text { density }\end{array}$ & SWE \\
m a.s.l. & $\mathrm{m}$ & $\mathrm{kg} \mathrm{m}^{-3}$ & $\mathrm{~m}$ & $\mathrm{~kg} \mathrm{~m}^{-3}$ & $\mathrm{~m}$ \\
\hline & & & & & \\
3755 & 0.14 & 450 & 0.17 & 850 & 0.208 \\
3800 & 0.41 & 384 & 0.15 & 850 & 0.285 \\
3835 & 0.90 & 396 & - & - & 0.357 \\
3890 & 0.76 & 341 & - & - & 0.259 \\
3925 & 1.02 & 348 & - & - & 0.355 \\
3960 & 1.10 & 353 & - & - & 0.388 \\
4000 & 0.98 & 324 & - & - & 0.318 \\
4050 & 1.41 & 328 & - & - & 0.462 \\
4120 & 1.10 & 325 & - & - & 0.358 \\
& & & & & \\
\hline
\end{tabular}

means of individual density measurements made in each pit and, therefore, underestimate the actual variability somewhat.

Because of the labor-intensive nature of digging and sampling snow pits, it is impossible to obtain a large density sample. However, many researchers have shown that density is conservative in relation to snow depth, and good estimations of SWE can be made with a few density measurements coupled with many depth measurements (Logan, 1973; Elder and others, 1989, 1991). A single density was assigned to each elevation zone and was used with the corresponding depth measurements to estimate within-zone SWE. The densities used in SWE estimations may be found in Table 1 with their respective zones. All SWE estimations reflect in inclusion of $0.16 \mathrm{~m}$ of superimposed ice found only in the lowest elevation zone,

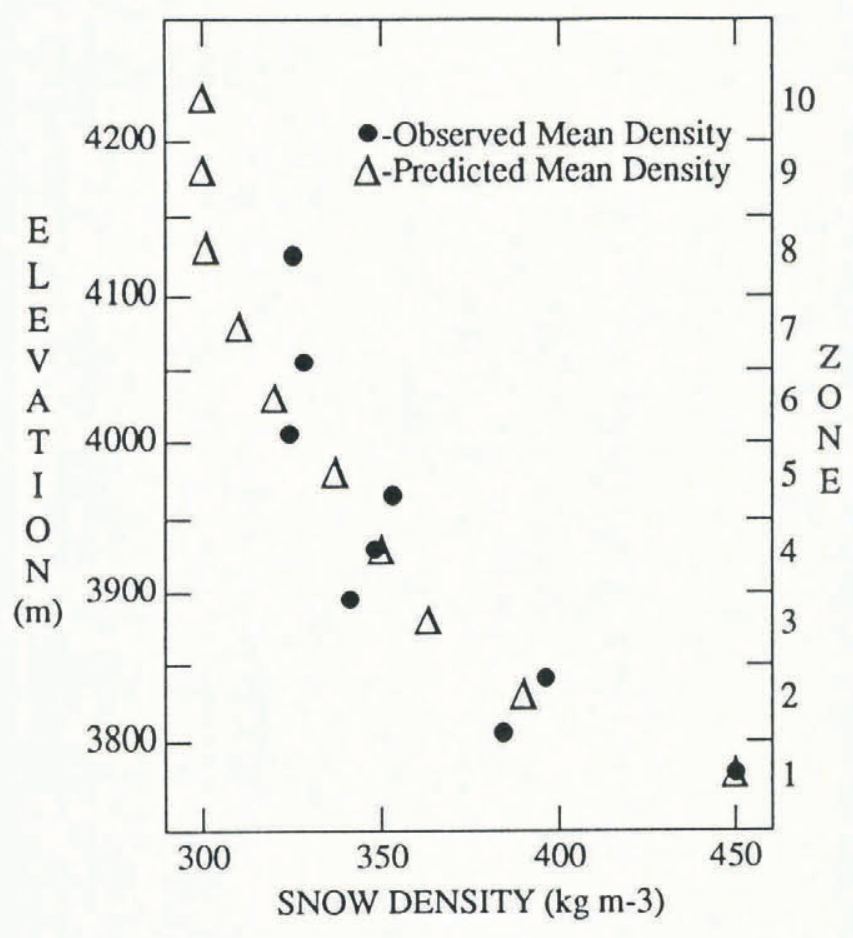

Fig. 2. Snow density versus elevation, east branch of Glacier No. 1, 15 May 1990. Observed snow densities are the mean values from snow-pit sites. Predicted snow densities are taken from the line fit to the observed values. These values were rounded to the nearest $10 \mathrm{~kg} \mathrm{~m}^{-3}$ and are listed in Table 1.

accounting for a total of $9970 \mathrm{~m}^{3} \mathrm{SWE}$ of about $0.01 \mathrm{~m}$ SWE averaged over the entire east branch area.

\section{Data sets}

Three sets of snow-depth data were used for all estimation procedures. The first set of depth measurements, referred to as set 1, included all high-resolution depth transects, totaling 1046 measurements, as described in the field methods section, but did not include the stake network data. The second set of data (set 2) consisted of the stake data, but was supplemented with data collected over all elevation ranges including a small subset of the transect data from set 1 . This set consisted of 198 depth measurements. The third set of depth data (set 3) consisted of only the stake data from the long-term network with a total of 45 depth measurements.

\section{METHODS OF ESTIMATING MASS BALANCE}

\section{Method 1}

The first method used stratification of the glacier by elevation into ten zones and assumed the mean of all depth measurements in each zone to be the snow depth for that zone. This value was multiplied by the appropriate density to give within-zone mean SWE $(\overline{S W E})$ :

$$
\overline{S W E_{j}}=\sum_{i=1}^{n} \frac{d_{i}}{n} \frac{\rho_{j}}{\rho_{\mathrm{w}}}
$$


where $\overline{S W E_{j}}$ is the mean snow water equivalence in zone $j, d$ is the depth of the $i_{\text {th }}$ measurement in zone $j, \rho_{j}$ is the density in zone $j, \rho_{\mathrm{w}}$ is the density of water, and $n$ is the number of depth measurements in zone $j$. Multiplying $\overline{S W E_{j}}$ by the zone area $A_{j}$ produced the total water stored as snow in each zone $j$, and total $S W E$ stored on the glacier was calculated by summing all the zones:

$$
S W E=\sum_{j=1}^{10} \overline{S W E_{j}} \mathrm{~A}_{j}=\sum_{j=1}^{10} \sum_{i=1}^{n} \frac{d_{i}}{n} \frac{\rho_{j}}{\rho_{\mathrm{w}}} A_{j} .
$$

The stake network covered the lower six elevation zones only, making it necessary to estimate $S W E$ for zones 7 through 10 in order to apply method 1 to the data set. Two different techniques were used to extrapolate $S W E$ from the network to higher elevations and these are discussed in detail below.

\section{Method 2}

The second method consisted of using the means for the entire input data sets. There is not within-zone or between-zone information from this technique. Mean depth was estimated by taking the mean of all depth data. Mean density was estimated by taking the area-weighted mean of the zone densities (Table 1). $\overline{S W E}$ is the product of these values (Equation (3)) and total $S W E$ was calculated by multiplying $\overline{S W E}$ by total glacier area (Equation (4)).

$$
\overline{S W E}=\sum_{i=1}^{N} \frac{d_{i}}{\mathrm{~N}} \bar{\rho} \quad \text { where } \bar{\rho}=\frac{\sum_{j=1}^{10} \frac{\rho_{j} A_{j}}{\rho_{\mathrm{w}}}}{\sum_{j=1}^{10} A_{j}}
$$

$$
S W E=\overline{S W E} A_{\text {total }} .
$$

\section{RESULTS AND DISCUSSION}

\section{Results from glacier subsection}

Depth data from all three data sets fell within elevation zones 1 through 6 , but the stake data had no points in elevation zones 7 through 10. A comparison of massbalance estimates between the three data sets has been made over zones 1 through 6 to evaluate sampling differences only, rather than introducing differences due to estimation procedures. This analysis is based on method 1 and Equations (1) and (2), where $j$ is summed over six, rather than ten, zones. From basic statistical properties, we expect a larger sample from a population to give us a more accurate estimate of the statistical properties of the population as a whole. Therefore, we will consider the estimates based on data set 1 to be the most accurate or "best" values, and we will compare the other data sets to set 1 results as the standard.

Total $S W E$ storage in each zone, calculated for each data set, is listed in Table 3 . Zone 1 shows a negligible difference between data sets and zone 2 is underestimated by sets 2 and 3 . Differences between data sets 1 and 3 in zone 3 , although greater in total volume, are smaller in $S W E$. Zone 4 shows significant differences between both data sets 1 and 3 , and set 2 . Set 2 underestimates set 1 by $0.09 \mathrm{~m} \overline{S W E}$ or between $18300 \mathrm{~m}^{3} S W E$. The largest differences in $\overline{S W E}$ are found in zone 6 where there is a $0.10 \mathrm{~m}$ discrepancy between set 1 and set 2 . The difference between set 1 and set 3 is also large. For the six zones as a whole, set 3 underestimates set 1 by $12400 \mathrm{~m}^{3}$ SWE or

Table 3. Results of mass-balance estimates from glacier subsection, comparison of zones 1 through 6 using method 1 and

\begin{tabular}{|c|c|c|c|c|c|c|c|}
\hline \multirow{4}{*}{ Zone } & \multicolumn{3}{|c|}{ Mass balance for data sets by zone } & \multicolumn{4}{|c|}{ Differences between data sets } \\
\hline & Set 1 & Set 2 & Set 3 & \multicolumn{2}{|c|}{$1-2$} & \multicolumn{2}{|c|}{$1-3$} \\
\hline & $S W E$ & SWE & $S W E$ & $S W E$ & $\overline{S W E}$ & $S W E$ & $\overline{S W E}$ \\
\hline & $\mathrm{m}^{3}$ & $\mathrm{~m}^{3}$ & $\mathrm{~m}^{3}$ & $\mathrm{~m}^{3}$ & $\mathrm{~m}$ & $\mathrm{~m}^{3}$ & $\mathrm{~m}$ \\
\hline 1 & 25000 & 25500 & 25500 & -500 & * & -500 & * \\
\hline 2 & 34000 & 30300 & 30300 & 3700 & 0.04 & 3700 & 0.04 \\
\hline 3 & 52500 & 53600 & 57500 & -1100 & 8 & -5000 & -0.03 \\
\hline 4 & 76700 & 58400 & 73300 & 18300 & 0.09 & 3400 & 0.02 \\
\hline 5 & 52600 & 46000 & 53000 & -6600 & -0.5 & 400 & $*$ \\
\hline 6 & 59700 & 44700 & 48500 & 15000 & 0.10 & 11200 & 0.08 \\
\hline Total SWE & 300500 & 258500 & 288100 & & & & \\
\hline$\overline{S W E}$ & 0.38 & 0.33 & 0.36 & & & & \\
\hline$\%$ error & & & & & & & \\
\hline
\end{tabular}
data sets 1, 2, and 3. For zones 1-6: data set 1, $n=650$; data set 2, $n=109$; data set 3, $n=45$. * indicates insignificant value $(\overline{S W E} \ll 0.01 \mathrm{~m})$ 
$4.1 \%$. Set 2 underestimates the best estimate of $S W E$ by $42000 \mathrm{~m}^{3}$ or $14.0 \%$, an amount equal to $0.05 \mathrm{~m} \mathrm{SWE}$.

Two interesting results follow from this analysis. First, it appears that the sparse stake network does an adequate job of estimating $S W E$ over the portion of the glacier covered by the stakes. This result is important because mass balance has been estimated from this network for a long period of time and this technique is used in many studies throughout the world. If accurate mass-balance determinations can be made from 45 stakes rather than the 650 data points found in the same area from the highresolution survey, then manpower and costs can be greatly reduced without compromising the results.

The second interesting result from this analysis is that the medium density survey (set 2) underestimated the best estimate of $S W E$ by a greater amount than the sparse stake network. Set 2 had 109 sample points in the same zones, over twice as many as the stake network. One possible explanation is that these additional samples used in set 2 were all collected on the east wall of the glacier, which is relatively steep and retains less snow because of continual avalanching and sloughing. This area is not represented by the stake network. The supplementary data were clearly not representative of the zones as a whole. The limited sampling introduced a strong bias to

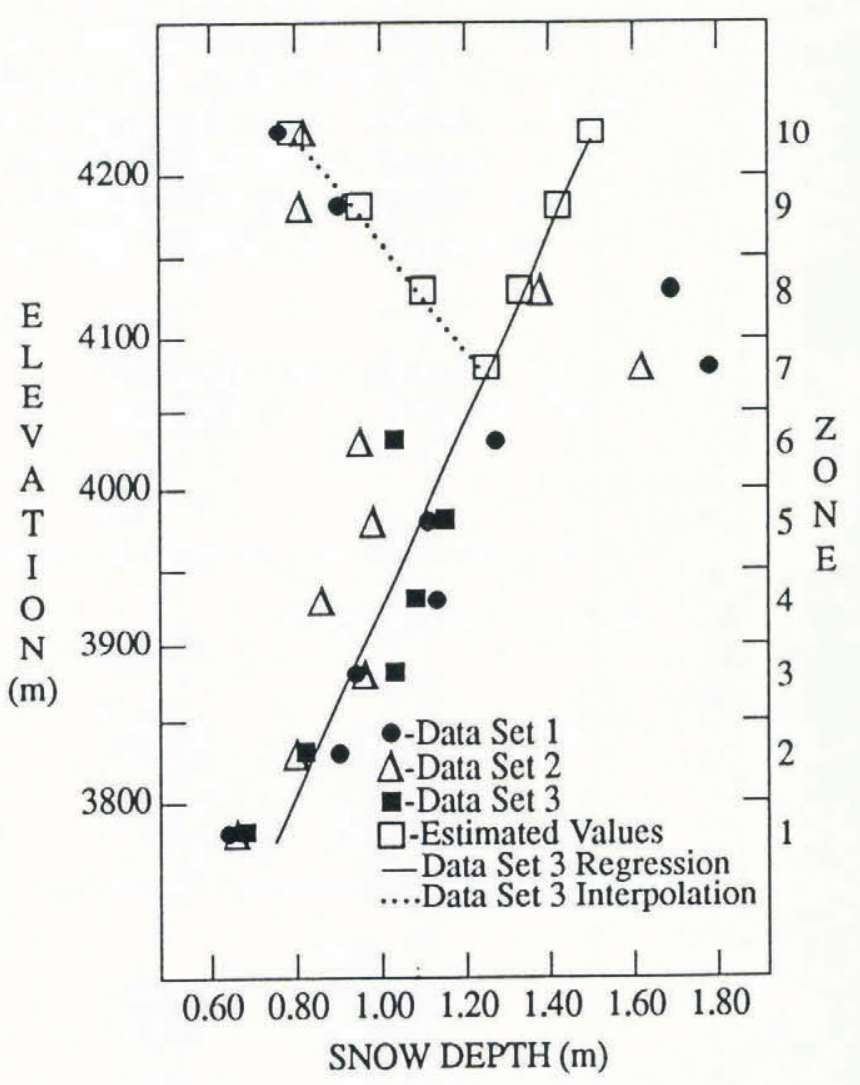

Fig. 3. Snow depth versus elevation, east branch of Glacier No. 1, 15 May 1990. Mean snow depth from each data set $(1,2$, and 3) are plotted against the mean elevation of the zone. The solid line represents the best fit by linear regression to the mean depths from the stake network (data set 3). The dotted line interpolates snow depth above the stake network and was forced through depth values of 1.25 and $0.80 \mathrm{~m}$ found at elevations of 4075 and $4225 \mathrm{~m}$, respectively. See text for further explanation. the data because of a small total sample size, indicating the importance of locating sample points optimally, both for permanent stakes and transects. Examination of Figure 3 shows that the mean zone $S W E$ for zones 3 through 6 (where the data sets differ) is significantly greater from the stake network than for set 2 .

\section{Results from entire east branch of glacier}

Results from estimations of mass balance for the entire east branch method 1 and data sets 1 and 2 are listed in Tables 4 and 5, respectively. Results from method 1 and data set 3 are listed in Tables 6 and 7, each presenting the results from a different extrapolation technique. Method

Table 4. Results from method 1 and data set 1. Massbalance estimates for each zone.

\begin{tabular}{lrccc}
\hline Zone & $n$ & Mean depth & SWE & SWE \\
& & $\mathrm{m}$ & $\mathrm{m}$ & $\mathrm{m}^{3}$ \\
& & & & \\
\hline & & & & \\
1 & 24 & 0.64 & 0.42 & 25000 \\
2 & 85 & 0.90 & 0.35 & 34000 \\
3 & 52 & 0.94 & 0.34 & 52500 \\
4 & 109 & 1.13 & 0.40 & 76700 \\
5 & 179 & 1.12 & 0.38 & 52600 \\
6 & 200 & 1.27 & 0.41 & 59700 \\
7 & 185 & 1.78 & 0.55 & 63500 \\
8 & 98 & 1.69 & 0.51 & 56800 \\
9 & 60 & 0.90 & 0.27 & 26700 \\
10 & 54 & 0.79 & 0.24 & 11100 \\
& & & & \\
Total & 1046 & 1.16 & 0.40 & 458600 \\
& & & & \\
\hline
\end{tabular}

Table 5. Results from method 1 and data set 2. Massbalance estimates for each zone

\begin{tabular}{rrrrr}
\hline Zone & $n$ & Mean depth & SWE & SWE \\
& & $\mathrm{m}$ & $\mathrm{m}$ & $\mathrm{m}^{3}$ \\
& & & & \\
\hline & & & & \\
1 & 11 & 0.66 & 0.43 & 25500 \\
2 & 9 & 0.80 & 0.31 & 30300 \\
3 & 8 & 0.96 & 0.35 & 53600 \\
4 & 28 & 0.86 & 0.30 & 58400 \\
5 & 27 & 0.98 & 0.33 & 46000 \\
6 & 26 & 0.95 & 0.30 & 44700 \\
7 & 43 & 1.62 & 0.50 & 57800 \\
8 & 24 & 1.38 & 0.41 & 46400 \\
9 & 15 & 0.81 & 0.24 & 24100 \\
10 & 7 & 0.81 & 0.24 & 11400 \\
& & & & \\
\hline
\end{tabular}


Table 6. Results from method 1 and data set 3. Massbalance estimates for each zone. Values in zones 7-10 are estimated on basis of an increase in SWE with elevation (see text)
Table 7. Results from method 1 and data set 3. Massbalance estimates for each zone. Values in zones 7-10 are estimated on basis of a decrease in SWE with elevation (see text)

\begin{tabular}{|c|c|c|c|c|c|c|c|c|c|}
\hline Zone & $n$ & Mean depth & $\overline{S W E}$ & SWE & Zone & $n$ & Mean depth & $\overline{S W E}$ & $S W E$ \\
\hline & & $\mathrm{m}$ & $\mathrm{m}$ & $\mathrm{m}^{3}$ & & & $\mathrm{~m}$ & $\mathrm{~m}$ & $\mathrm{~m}^{3}$ \\
\hline 1 & 11 & 0.66 & 0.43 & 25500 & 1 & 11 & 0.66 & 0.43 & 25500 \\
\hline 2 & 9 & 0.80 & 0.31 & 30300 & 2 & 9 & 0.80 & 0.31 & 30300 \\
\hline 3 & 6 & 1.03 & 0.37 & 57500 & 3 & 6 & 1.03 & 0.37 & 57500 \\
\hline 4 & 9 & 1.08 & 0.38 & 73300 & 4 & 9 & 1.08 & 0.38 & 73300 \\
\hline 5 & 6 & 1.13 & 0.38 & 53000 & 5 & 6 & 1.13 & 0.38 & 53000 \\
\hline 6 & 4 & 1.03 & 0.33 & 48500 & 6 & 4 & 1.03 & 0.33 & 48500 \\
\hline 7 & 0 & 1.25 & 0.39 & 44600 & 7 & 0 & 1.25 & 0.39 & 44600 \\
\hline 8 & 0 & 1.33 & 0.40 & 44700 & 8 & 0 & 1.10 & 0.33 & 37300 \\
\hline 9 & 0 & 1.42 & 0.43 & 42200 & 9 & 0 & 0.95 & 0.29 & 28200 \\
\hline 10 & 0 & 1.50 & 0.45 & 21200 & 10 & 0 & 0.80 & 0.24 & 11300 \\
\hline
\end{tabular}

2 results, using all three data sets, are averages over the entire glacier without zoning by elevation. Results are listed in Table 8, which summarizes the results from all estimation methods. Again, we will make the assumption that the zones used in method 1 coupled with the highresolution data (set 1) produce the most accurate estimate of mass balance and we will compare the other estimates to this "best"value.

Method 1 and data set 1 (Tables 4 and 8 ) indicate a mean snow depth of $1.16 \mathrm{~m}$ and $\overline{S W E}$ of $0.40 \mathrm{~m}$, resulting in about $458600 \mathrm{~m}^{3}$ of water stored as snow and superimposed ice on the glacier surface. Method 2 and data set 1 (Table 8) use the mean of all 1046 depth measurements and overestimates the best estimate by $7.8 \%$, indicating the value of including elevation zones in the modeling process. Method 1 and data set 2 produce a value differing from the best estimate by almost $61000 \mathrm{~m}^{3}$, which translates a $13.2 \%$ error (Tables 5 and $8)$. Interestingly, the mean of data set 2 used with method 2 produces a smaller error of only $0.03 \mathrm{~m} \overline{S W E}$ or a $5.2 \%$ underestimate. Comparison of Tables 4 and 5 show that the differences for individual zones are not great and the largest differences occur in zones 4 and 6 (see also Table $3)$. Seven of the ten zones are underestimated, resulting in a large net error.

Method 1, using only the stake network data (set 3), provided a range of errors depending on the technique used to extrapolate the stake data to the higher elevations. Extrapolating the mean depth from the stake network over the entire glacier, method 2, underestimates $\overline{S W E}$

Table 8. Mass-balance results from all estimation methods. Estimates and differences are for the entire glacier

Mass-balance estimates

Method/data set n Mean depth

$\overline{S W E} \quad$ Total SWE

$m^{3}$

m

0.40

1.16

method 1, data set 1 method 2, data set 1 method 1, data set 2 method 2, data set 2 method 1 , data set $3^{\dagger}$ method 1 , data set $3^{+}$ method 2, data set 3

$\begin{array}{rrr}1046 & 1.16 & 0.40 \\ 1046 & 1.25 & 0.43 \\ 198 & 0.97 & 0.34 \\ 198 & 1.10 & 0.37 \\ 45 & 1.07 & 0.38 \\ 45 & 0.98 & 0.35 \\ 45 & 0.94 & 0.32\end{array}$

Differences from method 1 , data set 1

$\overline{S W E} \quad$ Total SWE $\%$ diff.

$\mathrm{m} \quad \mathrm{m}^{3}$

${ }^{\dagger}$ mass-balance estimates using alternative estimation techniques with data set 3 (see text). 
by $0.08 \mathrm{~m}$ giving a value of $0.32 \mathrm{~m}$, resulting in a $19.0 \%$ error compared to the best estimate (Table 8 ). If only densities from the network area are used, the greater mean density of $357 \mathrm{~kg} \mathrm{~m}^{-3}$ produces an underestimate of $0.06 \mathrm{~m}$ and an error of about $15 \%$.

The stake network (data set 3 ) covers about half of the glacier's surface area and encompasses the lower half of the glacier's elevation range $(3750-4000 \mathrm{~m})$. For this reason the available stake data must be extrapolated to the higher elevations and surface area not represented by the stake network. For application of method 1 to data set 3, two extrapolation techniques were used to estimate SWE in zones 7 through 10 . For the first technique, we make the assumption that snow depth increases with elevation, a common assumption in many snow hydrology applications (U.S. Army Corps of Engineers, 1956; Barry, 1981). We fit a linear regression to the snow depths for each of the six zones represented by the network, using the mean depths and the mean elevations (depth $=0.0017$ (elev) $-5.4835, \mathrm{R}^{2}=0.708, n=6$ ). Figure 3 shows the actual mean depths for zones 1 through 6 plotted against elevation. Based on this model, snow depth was calculated for the mean elevations in zones 7 through 10. These snow depths were used to calculate $\overline{S W E}$ and total $S W E$ as described in method 1 by Equations (1) and (2). Table 6 lists the real data, estimated data and results. Table 8 shows that this technique was the closest to the best glacier-wide estimate, with an error of only $3.9 \%$ and a difference of only $0.02 \mathrm{~m} \overline{S W E}$, a result of averaging the individual zone errors over the entire glacier. Examination of zones 6 through 10 in Tables 4 and 6 show large differences between respective zones. The errors range between a $30 \%$ underestimate and a $91 \%$ overestimate, but the net effect is to cancel out the errors and provide a seemingly good total estimate. If all that is desired is a good estimate of total water storage as snow and superimposed ice, then extrapolation based on an increase in $S W E$ with elevation produces reasonable results. For snowmelt and glacier runoff predictions or equilibrium line altitude (ELA) estimations the accuracy of this technique is not sufficient.

The second estimation technique used with data set 3 assumed a linear decrease in $S W E$ with elevation from a point of maximum accumulation. Figure 3 shows that the maximum snow depth lies in zone 7 with a mean elevation of $4075 \mathrm{~m}$ for both data sets 1 and 2. Above this elevation the snow depth decreases to a value approximating that found in zone 2 (see also Tables 4 and 5). If we assume that depth decreases with increased elevation, we can apply the linear regression used above in the first technique to esimate depth in zone 7 where the maximum occurs, and then use another linear relation, based on the stake network data, to estimate the decreasing depth in zones 8,9 and 10. The linear relation forces a line through the value estimated by regression $(1.25 \mathrm{~m})$ at an elevation of $4075 \mathrm{~m}$ and the value of $0.80 \mathrm{~m}$ found at $4225 \mathrm{~m}$, taken from zone 2. SWE values in zones 8 and 9 were taken at the appropriate elevations intersecting this line. Table 7 lists the real data, estimated data and results. Table 8 shows that the predicted $\overline{S W E}$ of $0.24 \mathrm{~m}$ leads to an error of $10.8 \%$. Although estimation based on a linear decrease in $S W E$ with elevation produces a larger total error than increase in $S W E$ with elevation discussed above, the individual zone errors are smaller, and only zones 7 and 8 are seriously underestimated, by about $30 \%$ (compare Tables 4 and 7). The effect of cancelling errors found in the increase in $S W E$ with elevation technique does not occur because most of the errors in the decreasing technique are underestimates.

\section{Required sample size and distribution}

Sample size is an important factor in designing field surveys and in evaluating results. We have used the highresolution data set (set 1) to calculate the necessary sample size, $n^{\prime}$, required to be within a specified error range at a specified confidence level for snow-depth measurements in each of the ten zones (Cochran, 1977). We calculated $n^{\prime}$ for four accuracy levels: (1) a probable error $\leqslant 0.05 \mathrm{~m}$, (2) a probable error $\leqslant 0.10 \mathrm{~m}$, (3) a probable relative error $\leqslant 5 \%$ of the mean depth, and (4) a probable relative error $\leqslant 10 \%$ of the mean depth; all at the $90 \%$ confidence level. In other terms, for case 1 , out estimate of the mean depth would be within $0.05 \mathrm{~m}$ of the population depth $90 \%$ of the time if we took the recommended number of samples.

Sample sizes are listed in Table 9, along with the sample mean depth $(\bar{d})$, standard deviation $(\hat{\sigma})$, standard error of the mean depth $\left(\hat{\sigma}_{\bar{d}}\right)$, and coefficient of variation $(\mathrm{CV})$ for each zone. In most of the zones the coefficient of variation is relatively high. However, because of the large sample size, the standard error of the mean is small. In all ten zones the standard error is less than $6 \%$ of the mean depth and in eight out of the ten zones the $90 \%$ confidence interval (expressed as $\pm 2 \hat{\sigma}_{\bar{d}}$ ) is less than $10 \%$ of the mean depth. These statistics tell us that although the snow depth is variable on the glacier, we have obtained an accurate estimate of the mean depths in the zones by taking many samples.

Examination of Table 9 shows that in the first case, with an acceptable error of $0.05 \mathrm{~m}$ at the $90 \%$ confidence level, a large number of samples is required to satisfy the constraints. Of the 1452 samples, 1173 or about $81 \%$ fall in zones 5 through 8 . A sample requirement of this size is not likely to be operationally feasible, but is similar to our study and useful for research purposes. If an error of $0.10 \mathrm{~m}$ is acceptable, then only 375 measurements are necessary and a small field crew could complete a survey of this size in one day. An error of $5 \%$ of the mean depth also requires many samples (908) and is not practical. An error of $10 \%$ of the mean depth requires only 241 samples. It is noteworthy that our most relaxed constraints for calculating required sample size, that is a $90 \%$ probability of estimating the population mean depth within $10 \%$ of the mean, still requires 241 samples, or more than five times the amount of sample points in the permanent stake network. Although the stake network provides an estimate of the population mean with greater uncertainty or relative error, it does not mean that it is not valuable. The network serves as a long-term index, which can be calibrated to the true population mean by many possible techniques.

Although we have quantified sample size requirements, we have not done so for spatial distribution of sample points. Our results clearly show the importance of 
Table 9. Sample statistics and required sample sizes for within-zone snow depth based on results from data set 1

\begin{tabular}{|c|c|c|c|c|c|c|c|c|c|}
\hline Zone & $\mathrm{n}$ & $\bar{d}$ & $\mathrm{~m}$ & $\hat{\sigma}_{\bar{d}}$ & $\mathrm{CV}$ & $\begin{aligned} & n^{\prime} \\
\delta= & 0.05 \mathrm{~m} \\
\alpha= & 0.10\end{aligned}$ & $\begin{aligned} & n^{\prime} \\
\delta= & 0.10 \mathrm{~m} \\
\alpha & =0.10\end{aligned}$ & $\begin{aligned} & n^{\prime} \\
\delta= & 0.05 \overline{\mathrm{d}} \\
\alpha= & 0.10\end{aligned}$ & $\begin{aligned} & n^{\prime} \\
\delta= & 0.10 \overline{\mathrm{d}} \\
\alpha & =0.10\end{aligned}$ \\
\hline 1 & 24 & 0.640 & 0.2016 & 0.041 & 0.315 & 28 & 6 & 67 & 18 \\
\hline 2 & 85 & 0.898 & 0.2522 & 0.027 & 0.281 & 44 & 12 & 54 & 15 \\
\hline 3 & 52 & 0.944 & 0.2874 & 0.040 & 0.304 & 56 & 15 & 63 & 17 \\
\hline 4 & 109 & 1.128 & 0.2739 & 0.026 & 0.243 & 51 & 14 & 41 & 11 \\
\hline 5 & 179 & 1.124 & 0.5340 & 0.040 & 0.475 & 189 & 49 & 150 & 39 \\
\hline 6 & 200 & 1.276 & 0.6442 & 0.046 & 0.504 & 274 & 70 & 169 & 44 \\
\hline 7 & 185 & 1.775 & 0.8024 & 0.059 & 0.452 & 424 & 108 & 136 & 35 \\
\hline 8 & 98 & 1.687 & 0.6565 & 0.066 & 0.389 & 286 & 73 & 101 & 27 \\
\hline 9 & 60 & 0.895 & 0.3637 & 0.047 & 0.406 & 89 & 24 & 110 & 29 \\
\hline 10 & 54 & 0.789 & 0.1204 & 0.017 & 0.153 & 11 & 4 & 17 & 6 \\
\hline Total & 1046 & & & & & 1452 & 375 & 908 & 241 \\
\hline
\end{tabular}

$\mathrm{n}$ is the actual sample size for each zone from the survey, $\overline{\mathrm{d}}$ is the sample mean snow depth, $\hat{\sigma}$ is the sample standard deviation, $\hat{\sigma}_{\overline{\mathrm{d}}}$ is the standard error of the mean depth, $\mathrm{CV}$ is the coefficient of variation, $\mathrm{n}^{\prime}$ is the necessary sample size to be within the specified error, $\delta$ is a probable error, $1-\alpha$ is the confidence level.

sampling the entire glacier. All terrain variations such as slope, aspect, and elevation should be sampled because variability in these parameters controls variability in $S W E$ through accumulation, redistribution, and ablation. The greatest variation in snow depth occurs in the zones with the greatest mean depth, in the region of the ELA. This region of the glacier surface contains the areas most affected by avalanches, and many of the greatest depths recorded in the field were clearly located in avalanche debris. Avalanching and sloughing increase the variance in depth markedly by scouring starting zones and accumulation areas and by depositing greater than normal depths in runout areas. In designing surveys, it may be possible to take topography into account as an index for snow-depth variability, planning greater sample frequency in the areas with greater topographic variability. Decisions for accuracy requirements and resulting sample size must be tailored to the application and resources of the investigators.

\section{CONCLUSIONS}

An increase in precipitation and accumulation with an increase in elevation has long been recognized (Barry, 1981), and has been applied in many mass-balance studies. Good estimates of total mass balance can be obtained on this glacier from the stake network alone when a linear increase is applied to extrapolate SWE to the high elevations. However, individual zone errors from this technique suggest that a simple increase with elevation is not appropriate. It has also been shown that other effects such as redistribution of snow by wind and avalanching complicates the orographic effect (Elder and others, 1989, 1991; Wake, 1989). Observations on the glacier indicate that snow may be moved from the high steep portions of the glacier by avalanches with some regularity and wind redistribution may complement this effect. The data from the high-resolution survey covering the entire glacier surface show a decrease in $S W E$ as the greatest elevations are approached (Fig. 3). When a linear decrease is applied to the stake data at elevations above peak accumulation, an increased accuracy in the within-zone $S W E$ estimates follows.

Time and manpower are important considerations in designing field programs for mass-balance measurement on this glacier. There were large differences in the labor required to obtain the different data sets. The stake network was sampled for both depth and density by four people in 3 hours, giving a total of 12 man-hours. The high-resolution transects and additional snowpits required six people for 8 hours, or a total of 48 manhours. It can easily be argued that the results obtained from extrapolation of the stake network data are adequate for mass-balance requirements such as total runoff prediction, and it is difficult to justify the additional labor required for the high-resolution surveys. However, if applications require more detailed analysis, for example snowmelt modeling and predicting the timing of runoff, then a method that produces greater spatial or within-zone accuracy is needed. On larger glaciers high-resolution surveys may never be practical or possible and perhaps only remote sensing offers a hope of obtaining detailed spatial information.

Results from this study indicate that an accurate estimate of mass balance can be determined on the east 
branch of Glacier No. 1 with depth data collected from the permanent stake network alone. Accuracy is increased with sampling from the greater elevations not represented by the network. Terrain variation, elevation in this case, exerts some control on accumulation, redistribution, and ablation on this glacier and mass-balance estimates are improved using this parameter. It should be noted that these results are valid only for this date and the conditions observed. The results may apply to the glacier with different antecedent meteorological conditions or at different times in the accumulation and ablation season, but more field studies are needed before this assumption can be tested.

\section{AGKNOWLEDGEMENTS}

We would like to thank Kathy Tonnessen, Mark Williams and our colleagues in China for their help in the field. Jim Frew and Jeff Dozier provided the image-processing software. The work was supported by NASA's SIR-C and EOS programs, University of California Water Resources Center, Academia Sinica's Lanzhou Institute of Glaciology and Geocryology, and the USSR Academy of Science's Institute of Geography. Constructive reviews by Helgi Björnsson and two anonymous referees greatly improved the manuscript.

\section{REFERENCES}

Andrews, J. T. 1975. Glacial systems; an approach to glaciers and their environments. Belmont, CA, Wadsworth.

Barry, R. G. 1981. Mountain weather and climate. London and New York, Methuen.

Cochran, W. G. 1977. Sampling techniques. Third edition. New York, Wiley.

Echelmeyer, K. and Wang Zhongxiang. 1987. Direct observation of basal sliding and deformation of basal drift at sub-freezing temperatures. F. Glaciol., 33(113), 83-98.

Elder, K., J. Dozier and J. Michaelsen. 1989. Spatial and temporal variation of net snow accumulation in a small alpine watershed, Emerald Lake basin, Sierra Nevada, California, U.S.A. Ann. Glaciol., 13, 56-63.

Elder, K., J. Dozier and J. Michaelsen. 1991. Snow accumulation and distribution in an alpine watershed. Water Resour. Res., 27(7), 1541-1552.

Frew, J. and J. Dozier. 1986. The Image Processing Workbench - portable software for remote sensing instruction and research. In International Geoscience and Remote Sensing Symposium 1986. Proceedings. Paris, European Space Agency, 271-276. (ESA SP-254.)

Kotlyakov, V. M. and A. N. Krenke. 1982. Investigations of the hydrological conditions of alpine regions by glaciological methods. International Association of Hydrological Sciences Publication 138 (Symposium at Exeter 1982 - Hydrological Aspects of Alpine and High-Mountain Areas), 31-42.

Logan, L. 1973. Basin-wide water equivalent estimation from snowpack depth measurements. International Association of Hydrological Sciences Publication 107 (Symposium at Banff 1972 - Role of Snow and Ice in Hydrology), 864-884.

Paterson, W.S.B. 1981. The physics of glaciers. Second edition. Oxford, etc., Pergamon Press.

U.S. Army Corps of Engineers. 1956. Snow hydrology. Summary of report of snow investigations. Portland, OR, North Pacific Division. (PB-151660.)

Wake, C. P. 1989. Glaciochemical investigations as a tool for determining the spatial and seasonal variation of snow accumulation in the central Karakoram, northern Pakistan. Ann. Glaciol., 13, 279-284.

The accuracy of references in the text and in this list is the responsibility of the author/s, to whom queries should be addressed. 